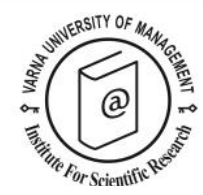

\title{
The impact of ethical leadership on counterproductivity among cabin crews
}

\section{Mona Bouzari ${ }^{1}$, Homayoun Pasha Safavi ${ }^{2 *}$ and Sanaz Vatankhah ${ }^{3}$}

\footnotetext{
${ }^{1}$ School of Tourism \& Hotel Management, European University of Lefke, Turkish Republic of Northern Cyprus, Turkey. E-mail: mbouzari@eul.edu.tr

2 Department of Business Administration, Faculty of Economics and Administrative Sciences, Cyprus International University, Turkish Republic of Northern Cyprus, Turkey. E-mail: hpsafavi@ciu.edu.tr

3 Faculty of aviation and space sciences, University of Kyrenia, Kyrenia, via Mersin 10, Turkey. E-mail: sanaz.vatankhah@kyrenia.edu.tr

${ }^{*}$ Corresponding author
}

\begin{abstract}
Underpinned by signalling theory, this study develops and tests a research model that posits personjob fit and person-organization fit as the mediators in the relationship between ethical leadership and counterproductive work behaviour. Through a quantitative research method and judgmental sampling, data were collected from 192 flight attendants in the private and public airline companies in Iran in three different waves. To control common method variance, this study applied procedural and statistical remedies. The results emerging from this study show that implementing ethical leadership behaviours by airline managers sends signals concerning ethical values of the organization among cabin crews which results in greater perceived ethical values fit in terms of person-organization and person-job fit. Cabin crews, who perceive high levels of fit with the job and the airline, are less expected to involve in counterproductive work behaviour. The study discusses theoretical implications and provides useful recommendations for managers in the airline industry.
\end{abstract}

Keywords: Ethical leadership, Person-Job fit, Person-Organization fit, Counterproductive work behaviour, Cabin crews

Citation: Bouzari, M., Safavi, H.P. and Vatankhah, S. (2020). The impact of ethical leadership on counterproductivity among cabin crews. European Journal of Tourism Research 25, 2507.

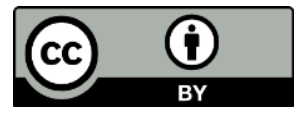




\section{Introduction}

Air transport industry experiences an ongoing increase in demand for such services as the International Air Transport Association (IATA) anticipated a substantial increase in passenger volume to reach over 4 billion in 2018 (Cheng, Chang, \& Chan, 2019). In spite of this growth in air transport industry, however, the rate of recruitment and training offered to cabin crews is considerably left behind leading to lower levels of service quality provided on board. Consequently, the existing cabin crews have to prolong their attendance hours and consequently face high job demands (Cheng et al., 2019; Hu, Hu, \& King, 2017). Moreover, in such environments, they are commonly affected by jetlag, dim light, and work overload which involve them in undesirable behaviours such as counterproductive work behaviour (Karatepe \& Vatankhah, 2014; Kim \& Back, 2012).

Counterproductive work behaviour that refers to "voluntary, potentially destructive or detrimental acts that hurt colleagues or organizations” (Spector \& Fox, 2002, p. 270) has inevitable drawbacks and economic costs for organizations (Griep, Vantilborgh, \& Jones, 2018). As estimated, the associated costs of counterproductive work behaviour are massive which lie between 17.6 (Hollinger \& Langton, 2006) and 200 billion dollars (Govoni, 1992 cited in Griep at al., 2018). Particularly, as confirmed by Hsieh et al. (2004), the airline industry has been a victim of this high economic costs and losses due to its specific work conditions. Given this fact, a number of scholars have attempted to investigate and reveal the antecedents of counterproductive work behaviour in organizations. This would also be attributed to its relation with various significant workplace and individual variables such as dark triad personalities, psychological contract breach and organizational justice (Ying \& Cohen, 2018), personality traits (van Zyl \& de Bruin, 2018), co-worker incivility (Moon \& Hur, 2018; Ferguson, 2012), and human resource management practices (Samnani \& Power, 2014). In a similar vein, results emerging from a meta-analytic study have suggested that poor leadership predicted propensity towards counterproductive work behaviour (Hershcovis et al., 2007). Specifically, among various leadership styles, ethical leaders' followers are less engaged in counterproductive work behaviours such as taking longer breaks, absenteeism and stealing official belongings (Bedi, Alpaslan, \& Green, 2016).

Ethical leadership is characterized as "the demonstration of normatively appropriate conduct through personal actions and interpersonal relationships, and the promotion of such conduct to followers through two-way communication, reinforcement, and decision making" (Brown, Treviño, \& Harrison, 2005, p. 120). Granted that ethical leadership has garnered increased attention among academics and practitioners, extant literature indicates that the heightened attention in endorsing ethical leadership is warranted (Walumbwa, Hartnell, \& Misati, 2017). Ethical leadership builds employees' efficacy and develop employees' potentiality to sort out conflict situations in the workplace (Babalola, Stouten, Euwema, \& Ovadje, 2018), reduces employee misconduct (Mayer, Kuenzi, \& Greenbaum, 2010), and lessens the social loafing of workforces while improving their performance (Byun, Karau, Dai, \& Lee, 2018). Additionally, ethical leaders seem to encourage the perception of person-organization fit and person-job fit. Person-organization fit is characterized as the consistency among people and the organization (Kristof, 1996) whereas person-job fit refers to the relationship between employee and job characteristics (Kristof-Brown, Zimmerman, \& Johnson, 2005). Prior studies have proven that person-organization fit and person-job fit at work are associated with several positive and favourable workplace and individual outcomes, which include satisfaction with the job, organizational commitment, higher level of work performance and lower intention to quit (e.g., Zhang, Lam, \& Deng, 2017; Astakhova, 2016; Oh et al., 2014). A review over the previous work also suggests that leaders (e.g., transformational leaders and empowering leaders) play a vital role in the perception of personorganization fit and person-job fit within organizations (Enwereuzor, Ugwu, \& Eze, 2018; Cai, Cai, 
Sun, \& Ma, 2018). However, as of today, not much attention has been given to the effect of ethical leadership and its relationship with person-organization fit and person-job fit with the main emphasis in the airline industry and cabin crews.

\section{Purpose and Contribution of the Study}

Conferring to signalling theory (Spence, 1973), it is presumed that ethical leaders, through their manners and conduction of ethical standards, will send a message to cabin crews that their ethical manners are recognized, valued and respected by the organization. This would lead to the perception of the fact that employees' personal values match organization's values and culture (personorganization fit) and the attributes would be fulfilled well in the current job (person-job fit) which in turn causes a lower level of counterproductive work behaviour. Hence, data collected from cabin crews in Iran is used to test (a) the effect of ethical leadership on person-organization fit and personjob fit; (b) the effect of person-organization fit and person-job fit on counterproductive work behaviour and (c) the mediating role of person-organization fit and person-job fit in the relation between ethical leadership and counterproductive work behaviour.

The contribution of the current study is multifaceted. Firstly, verified by previous recent investigations, regardless of the increasing interest in counterproductive work behaviour, our knowledge of its determinants remains inadequate (Ying \& Cohen, 2018; Cohen, 2016). More importantly, since cabin crews shape customers' perceptions of service quality and company's image (Moon, Hur, \& Jun, 2013), determining and understanding the factors that contribute to lessening the level of counterproductive work behaviour in the airline industry is worth investigating (Vatankhah, Javid, \& Raoofi, 2017).

Additionally, leadership is considered as a powerful force as well as an effective source of sustained competitive advantage (Avolio, 1999) for all businesses as they play an indispensable role in the incorporation of ethical behaviours and ethical values in the organizations (Yeşiltaş \& Tuna, 2018). The application of leadership is, indeed, apparent in the airline industry and various researchers have advocated the merits of adopting leadership styles (e.g., Smith, Minor, \& Brashen, 2018; Dewan, 2015). Explicitly, as a leading airline, Singapore Airlines is dedicated to the development of leadership programs to generate effective strategic leaders (Sengupta \& Sengupta, 2014). It is well warranted that ethical leaders are more qualified to integrate ethical behaviours and principles in the organization (Brown \& Treviño, 2006). However, an overview of the existing inquiries noticeably reveals that the role of ethical leaders in the airline industry and its effects on cabin crews' behaviours and performance has been largely ignored. Specifically, to the best authors' knowledge, no studies have inspected the impact of ethical leaders to the formation of person-organization fit as well as personjob fit in the case of cabin crews. This study would expand our knowledge regarding the application of ethical leadership and its effect on two mentioned facets of fit in airline industry. Improved insight into the role of ethical leaders could potentially assist scholars to determine probable antecedent that contributes to lessening level of counterproductive work behaviour.

Review of relative literature, in addition, demonstrated a dearth of research pertaining to the organizational level antecedent of counter productivity in the organization (O'Boyle, Forsyth, \& O'Boyle, 2011). Accordingly, this study bridges the research gap by proposing ethical leadership as an organizational level strategy to cope with counterproductive work behaviour.

Another contribution of the present inquiry is attributed to examining the significant linkage between ethical leadership and two mentioned facets of fit. In a recent inquiry conducted by Klaic, Burtscher, 
and Jonas (2018), the authors overtly suggested that there is a need to understand whether leaders have the contribution to the formation of fit with the workgroup.

Lastly, conferring to the target group and sample selection, as witnessed in previous inquiries, counterproductive work behaviour literature in developing countries (e.g., Iran) is at initial stages (LasisiOlukayode, Okuneye, \& Shodiya, 2014). More precisely, in a study conducted by Vatankhah et al., (2017), the authors explicitly mentioned the paucity of research with the focal emphasis of counterproductive work behaviour in the case of cabin crews in Iran. Accordingly, to fill this void, the present study adds value to the knowledge and literature by conducting an investigation among cabin crews in private and public airlines in Iran and advances the literature in several ways.

In a nut shell, the results to be derived from this inquiry are expected to contribute to the personorganization and person-job fit and framework as well as the counterproductive work behaviour research.

\section{Hypothesis development \\ Signalling theory}

Propositions based on signalling theory has long been endorsing the importance of organizational attributes and cues as sources of information for employees (Turban \& Greening, 1997). That is, employees' evaluation of organizational attributes sends signals about the working conditions in the organization (Bakhaus, Stone, \& Heiner, 2002) and organization's intentions or actions (Srivastava \& Lurie, 2001). Signalling theory is a well-known theory used to explain mechanism through which managers and organizational leaders send designated signals to their employees (Vatanhkah et al, 2017). That is, the application of supportive HR practices may act as signal of organizational good will for its members. Specifically, presence of ethical leadership in the organization transmits the signal of importance organization puts on ethical climate as well as behaviour in the organization.

Signalling theory, therefore, is deemed acceptable due to its predictive power to explain how organizational inputs are acting as signalling tools to stimulate positive organizational behaviour among employees. In addition, it appears that the management literature is devoid of proper application of this theory and the appropriateness of the theory in management and organizational literature deserves more elaboration. Accordingly, current study bridged the aforementioned research gap by transferring the tents of singling theory into leadership and organizational behaviour literature. In view of signalling theory (Spence, 1973), employees' positive evaluation of organizational inputs would serve as signals of the overall working condition of the firm. Corresponding to their positive evaluation, therefore, employees tend to react positively back to the organization. Similarly, it seems that the presence of ethical leadership in the organization provides signals by denoting organizational norms and values regarding an ethical work environment. Based on the abovementioned realization, we propose that ethical leadership in the organization is positively related to the perception of organizational moral values among cabin crews which then foster cabin crews' positive attitudes towards ethical behaviour. That is, in response to positive perception and evaluation of ethical leadership, cabin crews are more willing to follow the norms and less willing to engage in counterproductive work behaviour implied by signalling theory. It appears that leadership as a strong source of internal information is recognized by southwest airlines (Muduli \& Kaura, 2011). Signalling theory has been widely used to explain various organizational attributes and inputs as signals of organizational attractiveness to candidates (e.g., Allen, Mahto, \& Otondo, 2007; Turban \& Greening, 1997; Rynes, 1991; Rynes, Bretz, \& Gerhart, 1991). Despite its vast application and explanatory power, 
however, this theory has not been fully adopted by organizational scholars in the management literature (Connelly et al., 2011).

In light of signalling theory, it has been proposed and tested a conceptual model that proposes ethical leadership as a strategic remedy to cope with counterproductive work behaviour among cabin crews through enhanced person-job fit and person-organization fit perception. Ethical leadership is presumed to affect organizational citizenship behaviour, counterproductive work behaviour, task significance, job autonomy, organizational commitment, trust in and satisfaction with the leader, extra-role performance and ethical as well as unethical cognition and behaviour (Schaubroeck et al., 2012; Piccolo, Greenbaum, Hartog, \& Folger, 2010; Mayer, Kuenzi, Greenbaum, Bardes, \& Salvador, 2009; Ofori, 2009; Zhu, May, \& Avolio, 2004) and would be interpreted as positive signals of support from the organization. Hence, positive evaluation and recognition of organizational norms and values lead to lower levels of propensity to engage in dysfunctional work-related behaviour concerning sabotage, absenteeism or theft.

\section{Hypothesis}

Ethical leadership refers to "the demonstration of normatively appropriate conduct through personal actions and interpersonal relationships, and the promotion of such conduct to followers through twoway communication, reinforcement, and decision-making" (Brown et al., 2005, p. 120). According to Treviño, Hartman, and Brown (2000), the phenomenon of "moral manager" is considered as a part of ethical leadership which is concerned about leaders' transactional efforts in affecting followers' behaviour in a positive manner. Ethical leadership has been well-proposed to influence followers' ethical decision-making, prosocial behaviour and work attitudes in the form of satisfaction, motivation, and commitment to the organization (Brown \& Treviño, 2006). Review of recent literature convincingly positioned ethical leadership as a useful strategy to enhance attitudes and performance outcomes as well (e.g., Vullinghs, De Hoogh, Den Hartog, \& Boon, 2018; Moore et al., 2018; Hoch, Bommer, Dulebohn, \& Wu, 2018; Walumbwa et al., 2017; Johnson, 2017; Huang \& Paterson, 2017; Bedi et al., 2016; Demirtas \& Akdogan, 2015; Chughtai, Byrne, \& Flood, 2015; Shin, Sung, Choi, \& Kim, 2015; $\mathrm{Ng}$ \& Feldman, 2015). In their seminal work, Brown et al. (2005) suggest that ethical leadership positively affects several notable outcomes. In addition, review of the literature reveals that ethical leadership is positively related to perception of leader-member exchange, self-efficacy, organizational identification and performance (Walumbwa et al., 2017); perceptions of ethical context, ethical behaviour, job satisfaction, organizational citizenship behaviour and job engagement (Bedi et al., 2015); group ethical conduct, peer justice and group learning behaviour (Walumbwa et al., 2017); novel work behaviour (Yidong \& Xinxin, 2012) and negatively associated with turnover intentions and counterproductive work behaviour (Bedi et al., 2015).

The application of leadership is also evident in the airline industry (Smith et al., 2018; Dewan, 2015; Pearce, Wassenaar, \& Manz, 2014; Church, 1995). For instance, Ku, Chen, and Wei (2014) referred to a specific service design of flight attending position that requires high standards of team operation during the flight and suggests that shared leadership would positively affect the process through which transition process activities are related to enhanced team efficacy among cabin crews. As another facet of leadership in the organization, servant leadership has been found to be significantly linked with employee performance outcomes (Ashill, Rod, \& Carruthers, 20o8; Barbuto \& Wheeler, 2006). This is specifically the case among cabin crews who work as the front line service employee in the airline industry, since they require additional attention onboard the aircraft and presence of servant leadership fosters cabin crews' psychological capital, work engagement, service recovery performance and life satisfaction (Karatepe \& Talebzadeh, 2016). Moreover, the matter of the fact is 
that cabin crews are not only in charge of providing services during the flight, but they are mainly responsible for providing security and safety onboard the aircraft. Accordingly, leadership may positively foster cabin crews' willingness to engage in voice behaviour and upward safety communication with department managers (Chen, 2017). In addition, leadership is applied as a common managerial competence to inspire and empower employees, cut costs and provide excellent customer service in the southwest airlines (Cote, 2018; Pearce et al., 2014).

Generally speaking, provision of ethical conduct in the organization fosters fit between the organization and its employees (Valentine, Godkin, \& Lucero, 2002; Sims \& Kroeck, 1994) which is associated with "managing the psychological contracts between its employees and the organizations," "reinforcing the employee's organizational commitment," and "encouraging (creating and nurturing) an ethically- oriented organizational culture." (Sims, 1991, p.495). Accordingly, it is assumed that the application and provision of ethical leadership in the organization positively affects personorganization fit as well as person-job fit as employees often put more value on morality (Jose \& Thibodeaux, 1999; Vidaver-Cohen, 1998; Laufer \& Robertson, 1997). This proposition is consistent with the current findings where the significant association between ethical culture and perceived fit (e.g., Valentine et al., 2002; Schwepker, 2015; Ruiz-Palomino, Martı'nez-Canas, \& Fontrodona, 2013) has been well-established. In light of signalling theory (Spence, 1973), we propose that implementing ethical leadership behaviours by airline managers sends signals regarding ethical principles of the organization and accommodate core values among cabin crews (Brown \& Treviño, 2006) resulting in enhanced perceived ethical values fit in terms of person-organization fit and person-job fit.

Hypothesis 1: Ethical leadership is positively related to cabin crews' person-job fit.

Hypothesis 2: Ethical leadership is positively related to cabin crews' person-organization fit.

Person-organization fit and person-job fit are considered as two types of fit related to the umbrella concept of person-environment fit (Werbel \& Gilliland, 1999; Kristof, 1996; Judge \& Ferris, 1992). Person-job fit refers to "the match between the abilities of a person and the demands of a job or the needs/desires of a person and what is provided by a job" (Lauver \& Kristof-Brown, 2001) while personorganization fit is defined as "the compatibility between people and organizations that occurs when at least one entity provides what the other needs, they share similar fundamental characteristics or both" (Kristof, 1996, pp. 4-5). According to Da Silva, Hutcheson and Wahl (2010) perceived misfit with the job and the organizational strategies would result in less organizational commitment and intentions to stay among employees. High levels of fit perceived with one's values with the demands of the job and the values within the organization, on the other hand, alters employees' attitudes in terms of higher job satisfaction and lower turnover intentions (Lauver \& Kristof-Brown, 2001); enhanced affective commitment (Ruiz-Palomino et al., 2013; Meyer , Hecht , Gill, \& Toplonytsky , 2010) and lower unethical intent (Schwepker, 2017 \& 2015) as well as employees' outcomes as manifested by organizational citizenship behaviour (Ruiz-Palomino \& Martınez-Canas, 2014); task performance (Lauver \& Kristof-Brown, 2001); courteous behaviour (Farrell \& Oczkowski 2009) and contextual and overall job performance (Kristof-Brown et al., 2005; Goodman \& Svyantek, 1999). Despite the vast recognition and empirical investigation regarding consequences of perceived fit among employees, its' determining impact on counterproductive work behaviour known as deliberate dysfunctional actions targeting both the organization and its members (Spector et al., 2006), with some exceptions (e.g., Liu, Luksyte, Zhou, Shi, \& Wang, 2015) seems to be insufficient. Specifically, this type of deviant behaviour is sought to be evident in the airline industry (Vatankhah, Javid \& Raoofi, 2017) and its' antecedents deserve more empirical investigation among cabin crews. Accordingly, we propose that 
cabin crews who perceive high levels of fit with the job and the airline are less likely to engage in counterproductive work behaviour.

Hypothesis 3: Person-job fit is negatively related to counterproductive work behaviour among cabin crews.

Hypothesis 4: Person-organization fit is negatively related to counterproductive work behaviour among cabin crews.

Based on the abovementioned propositions, one can conclude that cabin crews' perceived person-job fit and person-organization fit may act as the mediator in the relationship between ethical leadership and counterproductive work behaviour. Assessing the proposed meditating effect is deemed appropriate as ethical leadership is significantly known "as primary mechanisms through which leaders embed their expectations and assumptions into the fabric of an organization" (Schaubroeck et al., 2012, p. 1068). That is, the presence of ethical leadership embeds ethical expectations and culture into the fit perceptions among cabin crews which directly and indirectly influence their behaviours. However, it appears that the mediating mechanism through which ethical culture and employee outcomes is related yet to be explored (Ruiz-Palomino et al., 2013; Schaubroeck et al., 2012).

According to Kish-Gephart, Harrison, and Trevino (2010), corporate ethical culture may be served as a remedy to unethical intentions among employees. Therefore, in light of signalling theory, we propose that presence of ethical leadership in the organization fosters cabin crews' perceived fit with the job and the airline company which this positive organization cue, in turn, results in lower propensity to engage in counterproductive work behaviour.

Hypothesis 5: The association between ethical leadership and counterproductive work behaviour is mediated by (a) person-job fit and (b) person-organization fit among cabin crews.

\section{Methodology}

To investigate public and private airlines in Iran, judgemental sampling was applied to collect data from cabin crews. Cabin crews are responsible to serve passengers onboard the aircraft, as well as ensuring their safety and security during the flight (Vatankhah et al., 2017). To get authorization for data collection, the research team sent a letter to managers and informed them about the main aim of the study.

To control common method variance, this study applied procedural and statistical remedies in line with guideline proposed by Podsakoff, MacKenzie, and Podsakoff (2012).

To reduce the common bias occurring due to the consistency motif (Podsakoff et al., 2012), a temporal separation was introduced between the measurement of the predictor, mediator and criterion variables. As such, data was gathered from cabin crews in three different waves through a one-week time lag. The time I questionnaires contained information about ethical leadership and demographic information of the respondents. Time II measured person-organization fit and person-job fit and counterproductive work behaviour was assessed in time III. As another procedural remedy, this study focused on protecting respondents' anonymity and tried to reduce evaluation apprehension and lessen social desirability and guaranteed them that there were no correct or wrong responses. Then respondents were asked to give back all questionnaires in sealed envelopes and put them in special boxes provided for this purpose. Moreover, an identification number was given to all cabin crews and they were asked to write their number on the questionnaires. These identification numbers enabled 
the research team to match different sets of questionnaires. This method has been applied in other recent studies (e.g., Safavi \& Bouzari, 2020, 2019; Safavi \& Karatepe, 2018; Bouzari \& Karatepe, 2017).

The researchers distributed 250 questionnaires in Time I, 242 questionnaires in Time II and 210 questionnaires in Time III. Totally, 192 questionnaires were received at the final stage. Compared to the total number of the questionnaires distributed in the first phase, the research team was able to receive a total number of 192 usable questionnaires ( $77.2 \%$ response rate).

As another remedy proposed by Podsakoff et al., (2012), different item scale was applied to measure the study constructs. Ethical leadership and counterproductive work behaviour were recorded on fivepoint scales whereas to measure person-organization fit and person-job fit, seven-point scale.

All three sets of questionnaires were subjected to the back-translation method suggested by McGorry (2000). As such, the Time I questionnaire was first prepared in English and then translated into Persian using the guidelines of the back-translation technique. This was also repeated for the Time II and Time III questions. A pilot study (five participants) was applied for understandability of the items. Each questionnaire was accompanied by a cover page. This page provided important information to respondents about confidentiality, anonymity and volunteer participation.

The majority of the respondents were between 28 to 37 years old (57.3\%), male (51.0\%), married (50.5\%), with a bachelor degree $(52.1 \%)$ and $34.1 \%$ have a tenure of one to five years.

\section{Measurements}

All items were used from the relevant empirical researches in the existing literature. Ethical leadership was taken from Brown, Treviño and Harrison (2005). Person-organization fit and person-job fit were taken from Cable and DeRue (2002) and counterproductive work behaviour was adapted from Bennett and Robinson (2000).

\section{Data analysis}

Structural equation modelling was utilized to evaluate the hypothesized relationships, using LISREL 8.30 (Joreskog \& Sorbom, 1996). LISREL is the most widespread and common statistical program for the analysis of structural equation models (Jöreskog, Sörbom, \& Du Toit, 2001). Therefore, it was applied as tool to reach a systematic and comprehensive analysis by modelling the relationships among the dependent and independent constructs simultaneously.

To analyse the data, a two-step approach was used (Anderson \& Gerbing, 1988). The initial tactic includes exploratory and confirmatory factor analysis which evaluates the validity of the constructs (Anderson \& Gerbing, 1988; Fornell \& Larcker, 1981). Composite reliability was arranged to check the internal consistency of all items (Bagozzi \& Yi, 1988). Based on the Chi-square difference test, the second step contained the comparison of two mediated models (full and partial).

\section{Results}

\section{Measurement results}

This section reports the psychometric properties of the measures. In confirmatory factor analysis, since some of the items had unacceptable standardized loadings $(<.50)$ or non-significant t-values, they have been discarded during confirmatory factor analysis and were not included for further analysis. This included two items from ethical leadership and six items from counterproductive work behaviour. Therefore, these items were not included in further analysis. The final results confirmed 
Table 1. Confirmatory factor analysis

\begin{tabular}{|c|c|c|c|c|c|}
\hline Items & $\begin{array}{l}\text { Standardized } \\
\text { loading }\end{array}$ & T-value & $\Phi^{2}$ & AVE & CR \\
\hline Ethical leadership & & & $-0.30-0.21$ & 0.86 & 0.98 \\
\hline Listens to what employees have to say & - & - & & & \\
\hline Disciplines employees who violate ethical standards & 0.87 & 16.74 & & & \\
\hline Conducts his/her personal life in an ethical manner & 0.94 & $17 \cdot 53$ & & & \\
\hline Has the best interests of employees in mind & 0.83 & 17.22 & & & \\
\hline Makes fair and balanced decisions & 0.91 & 17.24 & & & \\
\hline Can be trusted & 0.93 & 17.03 & & & \\
\hline Discusses business ethics or values with employees & 0.82 & 16.72 & & & \\
\hline $\begin{array}{l}\text { Sets an example of how to do things the right way in terms of } \\
\text { ethics }\end{array}$ & - & - & & & \\
\hline $\begin{array}{l}\text { Define success not just by results but also the way that they } \\
\text { are obtained }\end{array}$ & 0.82 & 16.97 & & & \\
\hline When making decisions, asks "what is the right thing to do?" & 0.78 & 16.95 & & & \\
\hline Person-organization fit & & & $-0.16-0.21$ & 0.89 & 0.96 \\
\hline $\begin{array}{l}\text { The things that I value in life are very similar to the things } \\
\text { that my organization values }\end{array}$ & 0.85 & $17 \cdot 72$ & & & \\
\hline $\begin{array}{l}\text { My personal values match my organization's values and } \\
\text { culture }\end{array}$ & 0.94 & 17.25 & & & \\
\hline $\begin{array}{l}\text { My organization's values and culture provide a good fit with } \\
\text { the things that I value in life, }\end{array}$ & 0.89 & 17.47 & & & \\
\hline Person-job fit & & & $-0.20-0.21$ & 0.88 & 0.95 \\
\hline $\begin{array}{l}\text { There is a good fit between what my job offers me and what I } \\
\text { am looking for in a job }\end{array}$ & 0.73 & 16.94 & & & \\
\hline $\begin{array}{l}\text { The attributes that I look for in a job are fulfilled very well by } \\
\text { my present job }\end{array}$ & 0.78 & 17.12 & & & \\
\hline $\begin{array}{l}\text { The job that I currently hold gives me just about everything } \\
\text { that I want from a job }\end{array}$ & 0.79 & 17.74 & & & \\
\hline Counterproductive work behavior & & & $-0.16--0.30$ & 0.86 & 0.98 \\
\hline Taken property from work without permission. & - & - & & & \\
\hline $\begin{array}{l}\text { Spent too much time fantasizing or day dreaming instead of } \\
\text { working. }\end{array}$ & - & - & & & \\
\hline $\begin{array}{l}\text { Taken an additional or longer break than is acceptable at } \\
\text { your workplace. }\end{array}$ & 0.78 & 17.05 & & & \\
\hline Littered your work environment. & 0.82 & 16.66 & & & \\
\hline Intentionally worked slower than you could have worked. & 0.81 & 16.95 & & & \\
\hline $\begin{array}{l}\text { Discussed confidential company information with an } \\
\text { unauthorized person. }\end{array}$ & 0.82 & 17.20 & & & \\
\hline Used an illegal drug or consumed alcohol on the job. & 0.85 & 17.24 & & & \\
\hline Put little effort into your work. & - & - & & & \\
\hline Neglected to follow your boss's instructions. & 0.88 & 16.90 & & & \\
\hline Made fun of someone at work. & - & - & & & \\
\hline Said something hurtful to someone at work. & 0.86 & 17.09 & & & \\
\hline Made an ethnic, religious, or racial remark at work. & - & - & & & \\
\hline Cursed someone at work. & 0.79 & 16.84 & & & \\
\hline Played a mean prank on someone at work. & 0.78 & 17.28 & & & \\
\hline Acted rudely toward someone at work. & - & - & & & \\
\hline Publicly embarrassed someone at work. & 0.86 & 17.08 & & & \\
\hline
\end{tabular}

Model fit statistics: $\chi^{2}=272.88 ; d f=246 ; \chi^{2} / d f=1.109 ; \mathrm{CFI}=0.99 ; \mathrm{PNFI}=0.87$ RMSEA $=0.024 ; \mathrm{GFI}=0.89 ; \mathrm{AGFI}=$ 0.87 ; SRMR $=0.028$.

All loadings are significant at the .o1 level.

(-) Dropped during confirmatory factor analysis.

the fact that there was an agreeable fit of the five-factor measurement model $\left(\chi^{2}=272.88 ; d f=246 ; \chi^{2} /\right.$ $d f=1.109$; CFI $=0.99$; PNFI = 0.87; RMSEA = 0.024; GFI = 0.89; AGFI = 0.87; SRMR = 0.028. $)$ KMO values were 0.943 which indicates the sample is adequate (Cerny \& Kaiser, 1977). Harman single factor test was applied to determine if common method variance was an issue in this study. In order to do 
so, all items related to ethical leadership, person-organization fit, person-job fit, and counterproductive work behaviour were loaded on a single factor. The single factor only explained $\mathbf{2 2} \%$ of the variance. This result proved that there was no threat of common method variance.

The results in Table 1 revealed that all observable indicators significantly loaded on their respective latent constructs. The average variances extracted (AVE) by ethical leadership, person-organization fit, and person-job fit and counterproductive work behaviour are above 0.50. Overall, the findings indicated that the measurement model possessed convergent validity.

The results showed that none of the shared variances between pairs of variables was greater than the AVEs for the two variables. Overall, the measurement model possessed discriminant validity (Nunkoo, Ramkissoon, \& Gursoy, 2013; Fornell \& Larcker, 1981). Composite reliability was greater than the accepted range (.6o). Thus, the results were reliable and approved the issue of convergent and discriminant validity.

Table 2 provides means, standard deviations, and correlations of observed variables. The overwhelming majority of the correlations between the variables were significant $(\mathrm{p}<0.05)$.

Table 2. Means, standard deviations, and correlations of observed variables

\begin{tabular}{|c|c|c|c|c|c|c|c|c|c|}
\hline Variables & 1 & 2 & 3 & 4 & 5 & 6 & 7 & 8 & 9 \\
\hline 1. $\quad$ Ethical leadership & - & & & & & & & & \\
\hline 2. Person-job fit & $0.153^{*}$ & - & & & & & & & \\
\hline 3. Person-organization fit & $0.206^{* *}$ & 0.043 & - & & & & & & \\
\hline $\begin{array}{l}\text { 4. Counterproductive work } \\
\text { behaviour }\end{array}$ & $0.294^{* *}$ & $-0.157^{*}$ & $0.198^{* *}$ & - & & & & & \\
\hline 5. Age & -0.096 & 0.112 & 0.057 & $0.182^{*}$ & - & & & & \\
\hline 6. Gender & $0.166^{*}$ & -0.113 & $0.192^{* *}$ & 0.020 & 0.011 & - & & & \\
\hline 7. Marital status & 0.102 & 0.031 & 0.004 & 0.006 & 0.135 & 0.115 & - & & \\
\hline 8. Education & -0.048 & -0.040 & -0.121 & 0.097 & 0.088 & -0.126 & -0.031 & - & \\
\hline 9. Organizational tenure & -0.098 & -0.101 & -0.100 & -0.013 & -0.109 & -0.096 & 0.032 & -0.071 & - \\
\hline Mean & 3.86 & 4.63 & 4.63 & 2.13 & 1.83 & 1.49 & 1.50 & 3.48 & 1.97 \\
\hline Standard deviation & 1.26 & 2.12 & 2.06 & 1.26 & 0.63 & 0.50 & 0.50 & 0.50 & 0.82 \\
\hline Cronbach's alpha & 0.98 & 0.96 & 0.95 & 0.98 & - & - & - & - & - \\
\hline
\end{tabular}

Note: Composite score was computed for each variable. ${ }^{*} \mathrm{p}<0.05,{ }^{* *} \mathrm{p}<0.01$ (two-tailed test).

Test of the Relationships in the Structural Model

Normality of the data was checked with skewness and kurtosis. The skewness values (ethical leadership -1.339, person-organization fit -0.782, person-job fit -0.79o and counterproductive work behaviour 1.381) were below 3.00 (Kline, 2011). The kurtosis values (ethical leadership -0.094, personorganization fit 01.232, person-job fit -1.183 and counterproductive work behaviour -0.006) were acceptable (ranging from -2 to +2 ) (George \& Mallery, 2010). Accordingly, there was proof of the normality of data.

A comparison was made between two proposed models, namely full and partial mediated model. It seemed that the fully mediated model $\left(\chi^{2}=280.94, d f=248\right)$ has a better fit than the other mediated model, namely partial one $\left(\chi^{2}=271.46, d f=247\right)$. Overall, fit statistics for the fully mediated model was quite satisfactory which was as: $\chi^{2}=280.94, d f=284, \chi^{2} / d f=0.98 ; \mathrm{CFI}=0.98$; IFI $=0.99$; GFI $=0.89$; $\mathrm{AGFI}=0.87$; RMSA $=0.026 ; \mathrm{SRMR}=0.042$. 
The findings from structural equation modelling provide support for direct and mediating effects. Specifically, ethical leadership shows a positive association with person-organization fit $(\beta=0.16, t$ $=2.12$ ) and person-job fit $(\beta=0.21, t=2.84)$. Consequently, hypothesis 1 and 2 are supported. Personorganization fit has a positive effect on counterproductive work behaviour $(\beta=-0.16, t=-2.15)$. This finding supports hypothesis 3. Moreover, person-job fit has a positive effect on counterproductive work behaviour $(\beta=0.20, t=-2.73)$. This finding supports hypothesis 4 .

In addition, the Sobel test results provide support for the mediating effects. Person-organization fit is a full mediator between ethical leadership and counterproductive work behaviour $(z$ score $=2.51)$ and person-job fit is a full mediator between ethical leadership and counterproductive work behaviour (z score $=1.96)$. Hence, hypothesis $5 \mathrm{a}$ and $5 \mathrm{~b}$ are supported.

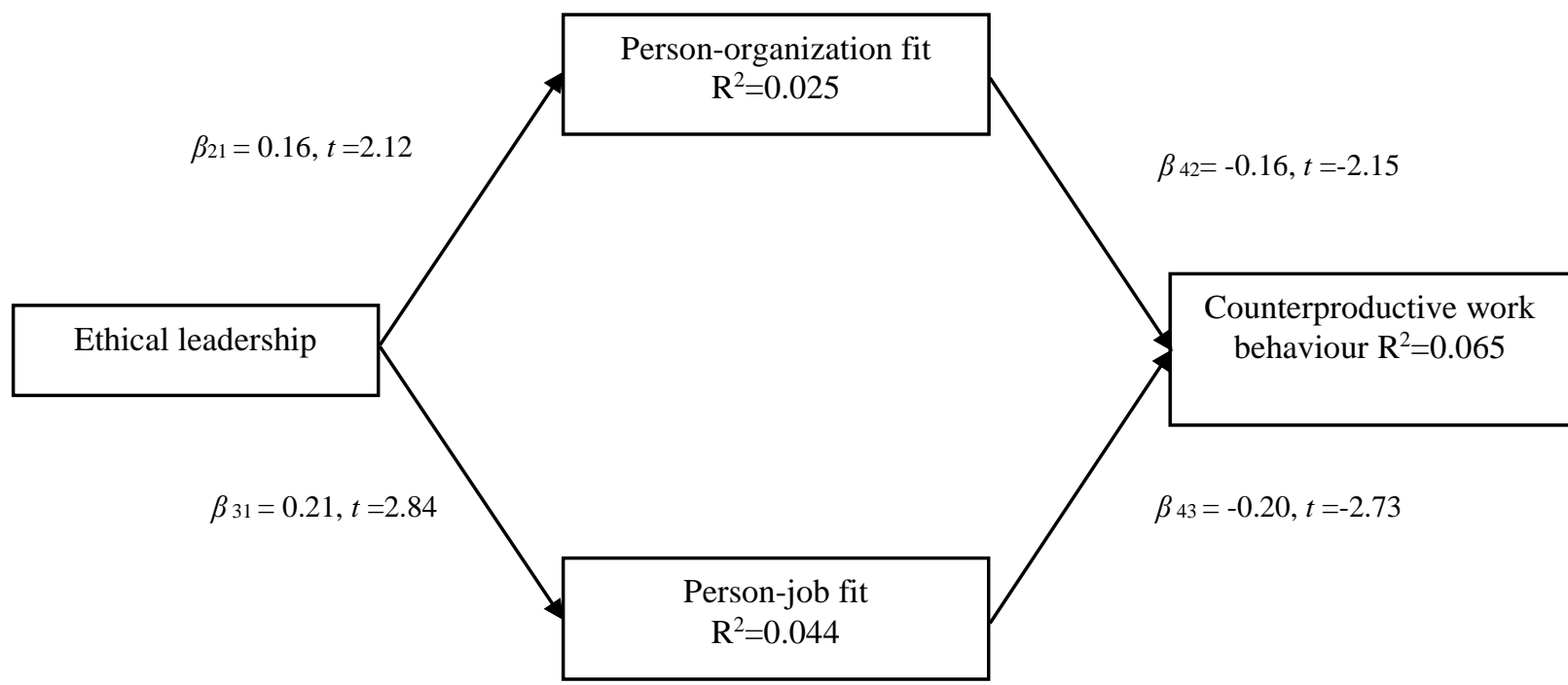

Model fit statistics:

$\chi^{2}=280.94, d f=284, \chi^{2} / d f=0.98 ; \mathrm{CFI}=0.98 ; \mathrm{IFI}=0.99 ; \mathrm{GFI}=0.89 ; \mathrm{AGFI}=0.87 ; \mathrm{RMSEA}=0.026 ; \mathrm{SRMR}$ $=0.042$.

Ethical leadership $\rightarrow$ person-job fit $\rightarrow$ counterproductive work behaviour z-score

Ethical leadership $\rightarrow$ person-organization fit $\rightarrow$ counterproductive work behaviour

Figure 1. Structural model test results

To confirm the mediation effect, this study applied bootstrapping technique with a bootstrapped 5,000 sample size via the $95 \%$ confidence interval (Hayes, 2013). Results confirmed that none of the confidence intervals contained zero. For the mediation effect of person-organization fit, the indirect effect is -0.068, the lower level confidence interval is -0.141 and upper-level confidence interval is o.o11. Therefore, mediation effect of person-organization fit in the relationship between ethical leadership and counterproductive work behaviour has confirmed. For the mediation effect of person-job fit, the indirect effect is -0.o88, the lower level confidence interval is -0.158 and upper-level confidence interval is -o.oog. Accordingly, person-job fit is a mediator between ethical leadership and counterproductive work behaviour. 
Table 3. Bias-correlated bootstrapping results

\begin{tabular}{llll}
\hline Hypothesized mediating relationship & $\begin{array}{l}\text { Indirect } \\
\text { effect }\end{array}$ & LLCI & ULCI \\
\hline $\begin{array}{l}\text { Ethical leadership } \rightarrow \text { person-organization fit } \rightarrow \\
\text { counterproductive work behaviour }\end{array}$ & -0.068 & -0.141 & 0.011 \\
$\begin{array}{l}\text { Ethical leadership } \rightarrow \text { person-job fit } \rightarrow \\
\text { counterproductive work behaviour }\end{array}$ & -0.088 & -0.158 & -0.009 \\
\hline
\end{tabular}

Note: Bias-Correlated Bootstrapping analysis was made with a bootstrapped 5.000 sample at $95 \%$ confidence interval.

Lower level confidence interval $=$ LLCI

Upper level confidence interval= ULCI

\section{Discussion}

The current study investigated the impact of ethical leadership on counterproductive work behaviour through the mediating effect of person-organization fit and person-job fit using data collected from cabin crews in Iran. The emerging results from the hypothesis testing propose that the data support all the hypothesized relationships. More precisely, congruent with signalling theory (Spence, 1973), the results suggest that implementing ethical leadership by airline managers sends signals concerning ethical values of the organization among cabin crews (Brown \& Treviño, 2006) which results in greater perceived ethical values fit in terms of person-organization fit and person-job fit. Cabin crews, who perceive high levels of fit with the job and the airline, are less expected to involve in counterproductive work behaviour. The results also attested that the presence of ethical leadership embeds ethical expectations and culture into the fit perceptions among cabin crews which indirectly influence their behaviours, expressed in lower levels of a tendency to engage in counterproductive work behaviour.

The conception of ethical behaviour in the organization promotes fit between the organization and its employees (Valentine et al., 2002). The study findings evidently approved the previous findings where the significant positive relationship between ethical culture and perceived fit have been debated (e.g., Schwepker, 2015; Ruiz-Palomino et al., 2013). Followers of ethical leaders put more value on morality which directly affects person-organization fit as well as person-job fit. This finding shows encouraging congruence with previous studies (e.g., Valentine et al., 2002; Sims \& Kroeck, 1994).

The results similarly proved that cabin crews, who perceive high levels of fit with the job and the organization, are less likely to engage in counterproductive work behaviour. To put it differently, in response to the positive perception of fit with the job and the airline, cabin crews are prone to react positively to the organization that can be manifested as following the norms and being less willing to involve in counterproductive work behaviour.

The results that both person-organization fit and person-job fit fully mediate the effect of ethical leadership on counterproductive work behaviour proposes that the existence of ethical leadership embeds ethical expectations and culture into the fit perceptions among cabin crews which directly and indirectly influence their behaviours. Followers of ethical leaders are supposed to be less involved in counterproductive work behaviour such as taking longer breaks, absenteeism and stealing official belongings (Bedi et al., 2016). In a nutshell, the results affirm that ethical leaders are able to lessen levels of cabin crews' tendency to engage in destructive or unfavourable acts that hurt other colleagues or airline through the perception of fit with the job and the organization. 


\section{Practical implications}

The results of the study represent practical implications appealing to airline companies and flight attending position. According to the results, it appears that leadership styles which are targeting moral conduct and ethical behaviour would result in lower propensity to engage in counterproductive work behaviour among cabin crews. Accordingly, airline managers at various managerial levels should place considerable importance to the leadership style they possess. In light of signalling theory (Spence, 1973), the more the leadership style is perceived to be ethical, the more positive signals are sent to cabin crews regarding ethical climate resulting in positive work behaviour in the organization. It appears that providing training programs which are focused on developing leadership skills and transforming managers into ethical leaders should be of great concern in the airline companies.

What is more, the emerging results revealed that perceived fit between cabin crews' personal values with those of the job and the organization is negatively associated with counterproductive work behaviour. Accordingly, several managerial remedies in terms of selective recruitment, mentoring and orientation programs, as well as training opportunities, may be used to boost the abovementioned fit perception. For instance, through situational judgement test in recruitment process, managers would let candidates experience the job and find out how they respond to 'real life' on-the-job scenarios. Managers also may use a standardized assessment as one of the ways to measure the level of employee fit with organization and job. Several pre-employment assessment tools that come in many shapes and sizes, such as 'Harver', 'Interview Mocha' and 'eSkill' (Hendrick, 2006) would enable managers on finding right candidates for cabin crew position. Presence of a number of high-performance work practices as organizational level strategies to enhance work behaviour while coping with dysfunctionality at the workplace is a common occurrence in leading airline companies (Solnet, Kandampully, \& Kralj, 2010; Wirtz, Heracleous, \& Pangarkar, 2008) and well-noticed in the relative literature (e.g., Vatankhah et al., 2017; Karatepe \& Vatankhah, 2014). As another remedy to minimize counterproductive behaviour is to create a work environment that has fair and equitable policies, which simply means everybody in the same position is subjected to the same rules. When employee notices that everybody has to abide by the same rule, the tendency towards engaging in counterproductive behaviour will lessen. In all, ethical leadership not only affects cabin crews' perceptions but also acts as a strategic managerial tool to cope with counterproductive work behaviour. With this realization, managers should notice the nature of the relationship they offer to their subordinates, and if a lower dysfunctionality is considered as the ultimate goal, then they should put emphasis on ethical leadership as the dominant leadership style in the organization.

\section{Limitations and future research}

This study faces several limitations which open doors to further research attempts. First, this study used ethical leadership to understand its impact on cabin crews' performance outcomes. However, other types of leadership styles may also affect cabin crews' attitudes and performance. Hence, it is suggested that the impact of other types of leadership in terms of transformational, servant and transactional leadership should be assessed in the study relationships. In addition, a review of the current literature revealed that the knowledge pertaining to mediating mechanisms through which leadership affects performance outcomes is yet scarce. Therefore, other perceptional mechanisms such as perceived ethical climate may enhance our understanding of the mediating mechanisms through which multiple leadership styles would result in less dysfunctionality at the workplace. Third, this study used a single cultural and occupational context which may raise the issue of generalizability. The application of cross-cultural as well as cross-occupational context would highly enhance the knowledge base regarding strategies appropriate to cope with counter productivity in the organizations. 


\section{References}

Aguinis, H., \& Glavas, A. (2013). Embedded versus peripheral corporate social responsibility: Psychological foundations. Industrial and Organizational Psychology, 6(4), 314-332.

Allen, D. G., Mahto, R. V., \& Otondo, R. F. (2007). Web-based recruitment: Effects of information, organizational brand, and attitudes toward a Web site on applicant attraction. Journal of Applied Psychology, 92(6), 1696-1708.

Anderson, J. C., \& Gerbing, D. W. (1988). Structural equation modeling in practice: A review and recommended two-step approach. Psychological Bulletin, 103(3), 411-423.

Ashill, N. J., Rod, M., \& Carruthers, J. (20o8). The effect of management commitment to service quality on frontline employees' job attitudes, turnover intentions and service recovery performance in a new public management context. Journal of Strategic Marketing, 16(5), 437-462.

Astakhova, M. N. (2016). Explaining the effects of perceived person-supervisor fit and personorganization fit on organizational commitment in the US and Japan. Journal of Business Research, 69(2), 956-963.

Avolio, B. J. (1999). Full leadership development: Building the vital forces in organizations. Sage.

Babalola, M. T., Stouten, J., Euwema, M. C., \& Ovadje, F. (2018). The relation between ethical leadership and workplace conflicts: The mediating role of employee resolution efficacy. Journal of Management, 44(5), 2037-2063.

Backhaus, K. B., Stone, B. A., \& Heiner, K. (2002). Exploring the relationship between corporate social performance and employer attractiveness. Business $\mathcal{E}$ Society, 41(3), 292-318.

Bagozzi, R. P., \& Yi, Y. (1988). On the evaluation of structural equation models. Journal of the Academy of Marketing Science, 16(1), 74-94.

Barbuto Jr, J. E., \& Wheeler, D. W. (2006). Scale development and construct clarification of servant leadership. Group \& Organization Management, 31(3), 300-326.

Bedi, A., Alpaslan, C. M., \& Green, S. (2016). A meta-analytic review of ethical leadership outcomes and moderators. Journal of Business Ethics, 139(3), 517-536.

Bennett, R. J., \& Robinson, S. L. (2000). Development of a measure of workplace deviance. Journal of Applied Psychology, 85(3), 349-360.

Bouzari, M., \& Karatepe, O. M. (2017). Test of a mediation model of psychological capital among hotel salespeople. International Journal of Contemporary Hospitality Management, 29(8), 2178-2197.

Brown, M. E., \& Treviño, L. K. (2006). Ethical leadership: A review and future directions. The Leadership Quarterly, 17(6), 595-616.

Brown, M. E., Treviño, L. K., \& Harrison, D. A. (2005). Ethical leadership: A social learning perspective for construct development and testing. Organizational Behaviour and Human Decision Processes, 97(2), 117-134.

Byun, G., Karau, S. J., Dai, Y., \& Lee, S. (2018). A three-level examination of the cascading effects of ethical leadership on employee outcomes: A moderated mediation analysis, Journal of Business Research, 88, 44-53.

Cable, D. M., \& DeRue, D. S. (2002). The convergent and discriminant validity of subjective fit perceptions. Journal of Applied Psychology, 87(5), 875-884.

Cai, D., Cai, Y., Sun, Y., \& Ma, J. (2018). Linking Empowering Leadership and Employee Work Engagement: The Effects of Person-Job Fit, Person-Group Fit, and Proactive Personality. Frontiers in Psychology, 9, 1-12

Cerny, B. A., \& Kaiser, H. F. (1977). A study of a measure of sampling adequacy for factor-analytic correlation matrices. Multivariate Behavioral Research, 12(1), 43-47.

Chen, S. C. (2017). Paternalistic leadership and cabin crews' upward safety communication: The motivation of voice behavior. Journal of Air Transport Management, 62, 44-53. 
Chughtai, A., Byrne, M., \& Flood, B. (2015). Linking ethical leadership to employee well-being: The role of trust in supervisor. Journal of Business Ethics, 128(3), 653-663.

Church, A. H. (1995). Linking leadership behaviours to service performance: Do managers make a difference. Managing Service Quality: An International Journal, 5(6), 26-31.

Cohen, A. (2016). Are they among us? A conceptual framework of the relationship between the dark triad personality and counterproductive work behaviors (CWBs). Human Resource Management Review, 26(1), 69-85.

Connelly, B. L., Certo, S. T., Ireland, R. D., \& Reutzel, C. R. (2011). Signalling theory: A review and assessment. Journal of Management, 37(1), 39-67.

Cote, R. (2018). Leadership Analysis: Southwest Airlines-Herb Kelleher, CEO. Journal of Leadership, Accountability \& Ethics, 15(1). 113-124.

Da Silva, N., Hutcheson, J., \& Wahl, G. D. (2010) Organizational Strategy and Employee Outcomes: A Person-Organization Fit Perspective. The Journal of Psychology, 144(2), 145-161.

Demirtas, O., \& Akdogan, A. A. (2015). The effect of ethical leadership behavior on ethical climate, turnover intention, and affective commitment. Journal of Business Ethics, 130(1), 59-67.

Dewan, N. (2015). A review of the literature Success story and leadership sort of Southwest Airlines. Global Journal of Research in Business \& Management, 2(1), 92-95.

Enwereuzor, I. K., Ugwu, L. I., \& Eze, O. A. (2018). How Transformational Leadership Influences Work Engagement Among Nurses: Does Person-Job Fit Matter? Western Journal of Nursing Research, 40(3), 346-366.

Farrell, M. A., \& Oczkowski, E. (2009). Service worker customer orientation, organization/job fit and perceived organizational support. Journal of Strategic Marketing, 17(2), 149-167.

Farrell, S., \& Hakstian, A. R. (2001). Improving salesforce performance: A meta-analytic investigation of the effectiveness and utility of personnel selection procedures and training interventions. Psychology \& Marketing, 18(3), 281-316.

Ferguson, M. (2012). You cannot leave it at the office: Spillover and crossover of coworker incivility. Journal of Organizational Behavior, 33(4), 571-588.

Fornell, C., \& Larcker, D. F. (1981). Evaluating structural equation models with unobservable variables and measurement error. Journal of Marketing Research, 18(1), 39-50.

George, D., \& Mallery, M. (2010). SPSS for Windows Step by Step: A Simple Guide and Reference. (10 ed.) Boston, Pearson.

Goodman, S. A., \& Svyantek, D. J. (1999). Person-organization fit and contextual performance: Do shared values matter. Journal of Vocational Behavior, 55(2), 254-275.

Govoni, S. J. (1992). To catch a thief. CFO, February, 24-32.

Griep, Y., Vantilborgh, T., \& Jones, S. K. (2018). The relationship between psychological contract breach and counterproductive work behavior in social enterprises: Do paid employees and volunteers differ? Economic and Industrial Democracy. 1-19.

Hayes, A. F. (2013). Introduction to mediation, moderation, and conditional process analysis: A regression-based approach. New York: Guilford Press.

Hendrick, R. Z. (2006). Evaluating Work Keys Profiling as a pre-employment assessment tool to increase employee retention. Old Dominion University.

Hershcovis, M. S., Turner, N., Barling, J., Arnold, K. A., Dupre', K. E., Inness, M., LeBlanc, M. M., \& Sivanathan, N. (2007). Predicting workplace aggression: A meta-analysis. Journal of Applied Psychology, 92(1), 228-238.

Hoch, J. E., Bommer, W. H., Dulebohn, J. H., \& Wu, D. (2018). Do ethical, authentic, and servant leadership explain variance above and beyond transformational leadership? A metaanalysis. Journal of Management, 44(2), 501-529. 
Hollinger, R. C., \& Davis, J. L. (2002). National retail security survey final report. Gainesville, Florida: University of Florida.

Hsieh, A. T., Liang, S. C., \& Hsieh, T. H. (2004). Workplace deviant behavior and its demographic relationship among Taiwan's flight attendants. Journal of Human Resources in Hospitality $\mathcal{E}$ Tourism, 3(1), 19-32.

Huang, L., \& Paterson, T. A. (2017). Group ethical voice: Influence of ethical leadership and impact on ethical performance. Journal of Management, 43(4), 1157-1184.

Johnson, C. E. (2017). Meeting the ethical challenges of leadership: Casting light or shadow. Sage Publications.

Joreskog, K., \& Sorbom, D. (1996). LISREL 8: User's Reference Guide. Chicago: Scientific Software International, Inc.

Jöreskog, K. G., Sörbom, D., \& Du Toit, S. H. C. (2001). LISREL 8: New statistical features. Scientific Software International.

Jose, A., \& Thibodeaux, M. S. (1999). Institutionalization of ethics: The perspective of managers. Journal of Business Ethics, 22(2), 133-143.

Judge, T. A., \& Ferris, G. R. (1992). The elusive criterion of fit in human resources staffing decisions. Human Resource Planning, 15(4), 47-68.

Karatepe, O. M., \& Talebzadeh, N. (2016). An empirical investigation of psychological capital among flight attendants. Journal of Air Transport Management, 55, 193-202.

Karatepe, O. M., \& Vatankhah, S. (2014). The effects of high-performance work practices and job embeddedness on flight attendants' performance outcomes. Journal of Air Transport Management, 37, 27-35.

Kish-Gephart, J. J., Harrison, D. A., \& Treviño, L. K. (2010). Bad apples, bad cases, and bad barrels: Meta-analytic evidence about sources of unethical decisions at work. Journal of Applied Psychology, 95(1), 1-31.

Klaic, A., Burtscher, M. J., \& Jonas, K. (2018). Person-supervisor fit, needs-supplies fit, and team fit as mediators of the relationship between dual-focused transformational leadership and well-being in scientific teams. European Journal of Work and Organizational Psychology, 27(5), 669-682.

Kline, R. B. (2011). Principles and Practice of Structural Equation Modeling, $3^{\text {rd }}$ ed. New York, NY: The Guilford Press.

Kristof, A. L. (1996). Person-organization fit: An integrative review of its conceptualizations, measurement, and implications. Personnel Psychology, 49(1), 1-49.

Kristof-Brown, A. L., Zimmerman, R. D., \& Johnson, E. C. (2005). Consequences of individuals' fit at work: a meta-analysis of person-job, person-organization, person-group, and person-supervisor fit. Personnel Psychology, 58(2), 281-342.

$\mathrm{Ku}$, E. C., Chen, F. H., \& Wei, K. (2014). Transition process activities and team efficacy of flight attendants. Journal of Air Transport Management, 40, 119-125.

LasisiOlukayode, J., Okuneye, M. Y., \& Shodiya, A. O. (2014). Antecedents of counter work behavior in public sector organizations: evidence from Nigeria. Kuwait Chapter of the Arabian Journal of Business and Management Review, 3(9), 58-66.

Laufer, W. S., \& Robertson, D. C. (1997). Corporate ethics initiatives as social control. Journal of Business Ethics, 16(10), 1029-1047.

Lauver, K. J., \& Kristof-Brown, A. (2001). Distinguishing between employees' perceptions of person-job and person-organization fit. Journal of vocational behavior, 59(3), 454-470.

Liu, S., Luksyte, A., Zhou, L., Shi, J., \& Wang, M. (2015). Overqualification and counterproductive work behaviors: Examining a moderated mediation model. Journal of Organizational Behavior, 36(2), 250-271. 
Mayer, D. M., Kuenzi, M., \& Greenbaum, R. L. (2010). Examining the link between ethical leadership and employee misconduct: The mediating role of ethical climate. Journal of Business Ethics, 95(1), 7-16.

Mayer, D. M., Kuenzi, M., Greenbaum, R., Bardes, M., \& Salvador, R. B. (2009). How low does ethical leadership flow? Test of a trickle-down model. Organizational Behavior and Human Decision Processes, 108(1), 1-13.

McGorry, S. Y. (2000). Measurement in a cross-cultural environment: survey translation issues. Qualitative Market Research: An International Journal, 3(2), 74-81.

Meyer, J. P., Hecht, T. D., Gill, H., \& Toplonytsky, L. (2010). Person-organization (culture) fit and employee commitment under conditions of organizational change: A longitudinal study. Journal of Vocational Behavior, 76(3), 458-473.

Minor, M., \& Brashen, H. (2018). Spiritual Leadership: A Guide to a Leadership Style That Embraces Multiple Perspectives. Journal of Instructional Research, 7, 80-89.

Moon, T. W., \& Hur, W. M. (2018). Go home and kick the dog: Spillover effects of experienced coworker incivility on customer-directed counterproductive work behavior. Journal of Service Theory and Practice, 28(5), 554-575.

Moon, T.W., Hur, W.M. and Jun, J.K. (2013). The role of perceived organizational support on emotional labor in the airline industry. International Journal of Contemporary Hospitality Management, 25(1), 105-123.

Moore, C., Mayer, D. M., Chiang, F. F., Crossley, C., Karlesky, M. J., \& Birtch, T. A. (2018). Leaders matter morally: The role of ethical leadership in shaping employee moral cognition and misconduct. Journal of Applied Psychology. 2-70.

Muduli, A., \& Kaura, V. (2011). Southwest Airlines Success: A Case Study Analysis. BVIMR Management Edge, 4(2). 115-118

Nancy Da Silva, Jennifer Hutcheson \& Gregory D. Wahl (2010) Organizational Strategy and Employee Outcomes: A Person-Organization Fit Perspective, The Journal of Psychology, 144(2), 145-161.

Ng, T. W., \& Feldman, D. C. (2015). Ethical leadership: Meta-analytic evidence of criterion-related and incremental validity. Journal of Applied Psychology, 100(3), 948-965.

Nunkoo, R., Ramkissoon, H., \& Gursoy, D. (2013). Use of structural equation modeling in tourism research: Past, present, and future. Journal of Travel Research, 52(6), 759-771.

O'Boyle, E. H., Forsyth, D. R., \& O'Boyle, A. S. (2011). Bad apples or bad barrels: An examination of group-and organizational-level effects in the study of counterproductive work behavior. Group $\mathcal{E}$ Organization Management, 36(1), 39-69.

Ofori, G. (2009). Ethical leadership: Examining the relationships with full range leadership model, employee outcomes, and organizational culture. Journal of Business Ethics, 90(4), 533-547.

Oh, I. S., Guay, R. P., Kim, K., Harold, C. M., Lee, J., Heo, C., \& Shin, K. (2014). Fit happens globally: A meta-analytic comparison of the relationships of person-environment fit dimensions with work attitudes and performance across East Asia, Europe, and North America. Personnel Psychology, $67,99-152$.

Ones, D. S. (2018). Counterproductive work behaviors 2.0: Assessment or consequences. International Journal of Selection and Assessment, 26(1), 1-4.

Pearce, C. L., Wassenaar, C. L., \& Manz, C. C. (2014). Is shared leadership the key to responsible leadership? Academy of Management Perspectives, 28(3), 275-288.

Piccolo, R. F., Greenbaum, R., Hartog, D. N. D., \& Folger, R. (2010). The relationship between ethical leadership and core job characteristics. Journal of Organizational Behavior, 31(2-3), 259-278.

Podsakoff, P. M., MacKenzie, S. B., \& Podsakoff, N. P. (2012). Sources of method bias in social science research and recommendations on how to control it. Annual Review of Psychology, 63, 539-569. 
Ruiz-Palomino, P., \& Martínez-Cañas, R. (2014). Ethical culture, ethical intent, and organizational citizenship behavior: The moderating and mediating role of person-organization fit. Journal of Business Ethics, 120(1), 95-108.

Ruiz-Palomino, P., Martínez-Cañas, R., \& Fontrodona, J. (2013). Ethical culture and employee outcomes: The mediating role of person-organization fit. Journal of Business Ethics, 116(1), 173188.

Rynes, S. L. (1991). Recruitment, job choice, and post-hire consequences: A call for new research directions. In M. D. Dunnette \& L. M. Hough (Eds.), Handbook of industrial and organizational psychology (pp. 399-444). Palo Alto, CA, US: Consulting Psychologists Press.

Rynes, S. L., Bretz Jr, R. D., \& Gerhart, B. (1991). The importance of recruitment in job choice: A different way of looking. Personnel Psychology, 44(3), 487-521.

Safavi, H. P., \& Bouzari, M. (2020). How Can Leaders Enhance Employees' Psychological Capital? Testing the Mediation Effect of Person-Group and Person-Supervisor Fit. Tourism Management Perspectives, 33, 100626

Safavi, H. P., \& Bouzari, M. (2019). The association of psychological capital, career adaptability and career competency among hotel frontline employees. Tourism Management Perspectives, 30, 6574 .

Safavi, H. P., \& Karatepe, O. M. (2018). High-performance work practices and hotel employee outcomes: the mediating role of career adaptability. International Journal of Contemporary Hospitality Management, 30(2), 1112-1133.

Samnani, A. K., \& Power, J. L. (2014). Reducing Thoughts of Revenge and Mistreatment: The Role of HRM Practices. In Academy of Management Proceedings (Vol. 2014, No. 1, p. 16178). Briarcliff Manor, NY 10510: Academy of Management.

Schaubroeck, J. M., Hannah, S. T., Avolio, B. J., Kozlowski, S. W., Lord, R. G., Treviño, L. K., Dimotakis, N., \& Peng, A. C. (2012). Embedding ethical leadership within and across organization levels. Academy of Management Journal, 55(5), 1053-1078.

Schwepker Jr, C. H. (2015). Influencing the salesforce through perceived ethical leadership: the role of salesforce socialization and person-organization fit on salesperson ethics and performance. Journal of Personal Selling E Sales Management, 35(4), 292-313.

Schwepker Jr, C. H. (2017). Psychological ethical climate, leader-member exchange and commitment to superior customer value: influencing salespeople's unethical intent and sales performance. Journal of Personal Selling E Sales Management, 37(1), 72-87.

Sengupta, N., \& Sengupta, M. (2014). Singapore Airlines: Gliding with People Excellence.

Setó-Pamies, D., \& Papaoikonomou, E. (2016). A multi-level perspective for the integration of ethics, corporate social responsibility and sustainability (ECSRS) in management education. Journal of Business Ethics, 136(3), 523-538.

Shin, Y., Sung, S. Y., Choi, J. N., \& Kim, M. S. (2015). Top management ethical leadership and firm performance: Mediating role of ethical and procedural justice climate. Journal of Business Ethics, 129(1), 43-57.

Sims, R. L., \& Kroeck, K. G. (1994). The influence of ethical fit on employee satisfaction, commitment and turnover. Journal of Business Ethics, 13(12), 939-947.

Sims, R. R. (1991). The institutionalization of organizational ethics. Journal of Business Ethics, 10(7), 493-506.

Smith, G., Minor, M., \& Brashen, H. (2018). Spiritual Leadership: A Guide to a Leadership Style That Embraces Multiple Perspectives. Journal of Instructional Research, 7, 80-89.

Solnet, D., Kandampully, J., \& Kralj, A. (2010). Legends of service excellence: The habits of seven highly effective hospitality companies. Journal of Hospitality Marketing E Management, 19(8), 889-908. 
Spector, P. E., \& Fox, S. (2002). An emotion-centered model of voluntary work behavior: Some parallels between counterproductive work behavior and organizational citizenship behavior. Human Resource Management Review, 12(2), 269-292.

Spector, P. E., Fox, S., Penney, L. M., Bruursema, K., Goh, A., \& Kessler, S. (2006). The dimensionality of counterproductively: Are all counterproductive behaviors created equal? Journal of Vocational Behavior, 38, 446-46o.

Spence, M. (1973). Job Market Signalling. The Quarterly Journal of Economics, 87(3). 355-374.

Srivastava, J., \& Lurie, N. (2001). A consumer perspective on price-matching refund policies: Effect on price perceptions and search behavior. Journal of Consumer Research, 28(2), 296-307.

Treviño, L. K., Hartman, L. P., \& Brown, M. (2000). Moral person and moral manager: How executives develop a reputation for ethical leadership. California Management Review, 42(4), 128-142.

Turban, D. B., \& Greening, D. W. (1997). Corporate social performance and organizational attractiveness to prospective employees. Academy of Management Journal, 40(3), 658-672.

Valentine, S., Godkin, L., \& Lucero, M. (2002). Ethical context, organizational commitment, and person-organization fit. Journal of Business Ethics, 41(4), 349-360.

van Zyl, C. J. J., \& de Bruin, G. P. (2018). Predicting counterproductive work behavior with narrow personality traits: A nuanced examination using quantile regression. Personality and Individual Differences, 131, 45-50.

Vatankhah, S., Javid, E., \& Raoofi, A. (2017). Perceived organizational support as the mediator of the relationships between high-performance work practices and counter-productive work behavior: Evidence from airline industry. Journal of Air Transport Management, 59, 107-115.

Vidaver-Cohen, D. (1998). Moral climate in business firms: A conceptual framework for analysis and change. Journal of Business Ethics, 17(11), 1211-1226.

Vullinghs, J. T., De Hoogh, A. H., Den Hartog, D. N., \& Boon, C. (2018). Ethical and Passive Leadership and Their Joint Relationships with Burnout via Role Clarity and Role Overload. Journal of Business Ethics, 1-15.

Walumbwa, F. O., Hartnell, C. A., \& Misati, E. (2017). Does ethical leadership enhance group learning behavior? Examining the mediating influence of group ethical conduct, justice climate, and peer justice. Journal of Business Research, 72, 14-23.

Werbel, J. D., \& Gilliland, S. W. (1999). Person-environment fit in the selection process. Research in Human Resources Management, 17, 209-243.

Wiernik, B. M., \& Ones, D. S. (2018). Ethical employee behaviors in the consensus taxonomy of counterproductive work behaviors. International Journal of Selection and Assessment, 26(1), 3648.

Wirtz, J., Heracleous, L., \& Pangarkar, N. (2008). Managing human resources for service excellence and cost effectiveness at Singapore Airlines. Managing Service Quality: An International Journal, 18(1), 4-19.

Yeșiltaş, M., \& Tuna, M. (2018). The effect of ethical leadership on service sabotage. The Service Industries Journal, 1-27.

Yidong, T., \& Xinxin, L. (2013). How ethical leadership influence employees' innovative work behavior: A perspective of intrinsic motivation. Journal of Business Ethics, 116(2), 441-455.

Ying, L., \& Cohen, A. (2018). Dark triad personalities and counterproductive work behaviors among physicians in China. The International Journal of Health Planning and Management, 33(4), 985998.

Zhang, L., Lam, C. F., \& Deng, Y. (2017). Leader-member exchange and guanxi are not the same: differential impact of dyadic relationships on fit perceptions, helping behavior, and turnover intention. The International Journal of Human Resource Management, 28(7), 1005-1030. 
Zhu, W., May, D. R., \& Avolio, B. J. (2004). The impact of ethical leadership behavior on employee outcomes: The roles of psychological empowerment and authenticity. Journal of Leadership $\mathcal{E}$ Organizational Studies, 11(1), 16-26.

Received: 12/06/2019

Accepted: 17/12/2019

Coordinating editor: Martina Gonzalez-Gallarza 